\title{
Can sea urchin grazing of kelp forests in the Arctic make rocky shore systems more vulnerable to oil spills?
}

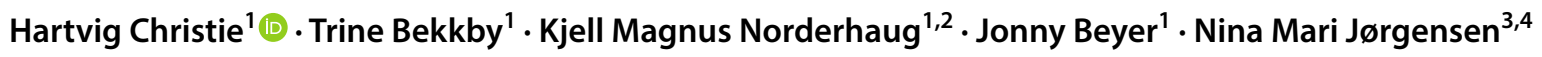

Received: 14 March 2018 / Revised: 14 December 2018 / Accepted: 18 December 2018 / Published online: 2 January 2019

(c) The Author(s) 2019

\begin{abstract}
In Arctic Norway, the risk of major marine oil spills associated with increasing offshore drilling, land terminal, and maritime transport activities is a cause for concern. Intertidal and subtidal kelp and seaweed communities found in this region are highly productive ecosystems, although sea urchin (Strongylocentrotus droebachiensis)-overgrazed areas (urchin barrens) have been and still are a widespread problem. In the present study, we developed a kelp (Laminaria hyperborea) distribution model and studied fauna distribution, dispersal and recolonisation potentials in seaweed communities, kelp forests and sea urchin-grazed areas to assess sensitivity and vulnerability of these rocky shore communities to additional stress from oil spills, especially if the oil is released close to the coast. Our results suggest that sheltered and moderately exposed rocky shore seaweed communities close to urchin barrens are the most sensitive systems when a combined ecological effect from grazing and oil spill pollution is considered. Our study may have implications for which oil spill countermeasures that represent the best environmental practice (BEP) in the northern coastal areas that already are ecologically stressed because of sea urchin overgrazing.
\end{abstract}

Keywords Arctic coast $\cdot$ Kelp $\cdot$ Seaweed $\cdot$ Sea urchins $\cdot$ Vulnerability $\cdot$ Coastal management $\cdot$ Oil spill response $\cdot$ Spatial modelling $\cdot$ Combined effects

\section{Introduction}

The Arctic region is currently experiencing mounting pressure from offshore petroleum industrial activity. In Norway, the offshore petroleum industry is increasing their activities in the Barents Sea as the old fields in the North Sea and Norwegian Sea have become depleted. Offshore drilling and production activities, land terminals and new shipping routes have been established along the northernmost coast

Electronic supplementary material The online version of this article (https://doi.org/10.1007/s00300-018-02450-8) contains supplementary material, which is available to authorized users.

Hartvig Christie

hartvig.christie@niva.no

1 Norwegian Institute for Water Research (NIVA), Gaustadalléen 21, 0349 Oslo, Norway

2 Institute for Marine Research, 4817 His, Norway

3 Akvaplan-Niva, Fram centre, 9296 Troms $\varnothing$, Norway

4 Norwegian Polar Institute, Fram centre, 9296 Troms $\varnothing$, Norway facing the Barents Sea, especially close to the city of Hammerfest, at $70.7^{\circ} \mathrm{N}$ (Bambulyak et al. 2015). These trends call for environmental management and action plans that are adapted to marine oil spill situations in Arctic waters, coastlines and ecosystems.

Shallow subtidal coastal areas in northern Norway are dominated by rocky shores dominated by seaweed (Fucales) beds and kelp (Laminaria spp. and Saccharina latissima) forests. These vegetation systems support numerous ecosystem services of which communities of mobile invertebrate animals are of principal importance as food for coastal fish. The seaweed and kelp communities share many associated species that can migrate between them (Christie et al. 2009). But during the last four decades, a regime shift from highly productive kelp forest (Laminaria hyperborea) ecosystems to green sea urchin (Strongylocentrotus droebachiensis)dominated barren grounds has been observed along this coastline and in many coastal temperate and Arctic seas around the world (Skadsheim et al. 1995; Sivertsen 1997; Norderhaug and Christie 2009; Filbee-Dexter and Scheibling 2014; Ling et al. 2015), leaving patches of intact kelp only in the most wave-exposed locations, whereas less 
wave-exposed areas have been transformed to desert-like barrens. While many areas further south have recently shown recovery of kelp (Norderhaug and Christie 2009; Rinde et al. 2014), the overgrazed state of the traditionally kelp-dominated coastal system persists in the northernmost region of Norway.

It is unknown how such a stressed system will respond to the event of a second large-scale ecosystem perturbation, such as a major oil spill occurring along the coast, e.g., like the Exxon Valdez oil tanker accident in Alaska or the major Deepwater Horizon oil blowout situation in the Northern Gulf of Mexico. We hypothesise that the recovery potential of rocky shore ecosystems suffering from sea urchin grazing to oil contamination is low. In the event of a major oil spill at sea, surface slicks will form and spread with wind, waves and sea currents (Zobell 1963; Boufadel et al. 2006; $\mathrm{Li}$ et al. 2010). A key risk factor of marine oil slicks is their potential for reaching the shore and make landfall, as oil shoring is always associated with the increased impact level, and this problem is probably particularly true for cold water situations (e.g. Peterson et al. 2003; Yamamoto et al. 2003).

There has not yet been any major oil spill along the coast of northern Norway, and oil spill management plans must thus rely on experiences from elsewhere. Identifying the vulnerability of coastal habitats to oil contamination is challenging, as impacts of physical and biotic factors will vary considerably in time and space (Wieczorek et al. 2007). Some coastal habitats are found to be more sensitive than others to oil impacts, and oil spills tend to affect the intertidal zone (Gundlach and Heyes 1978). Detailed mapping and assessment of coastal habitats and their vulnerability to oil spills are therefore important parts of preparing for oil spill response operations, e.g. by the development of shoreline oil spill hazard maps (Alves et al. 2014). Exposed rocky headlands tend to be classified as having low vulnerability to oil spills, whereas sheltered rocky coasts are normally considered to be more at risk (e.g. Gundlach and Hayes 1978). However, as these vulnerability assessments are developed for intact ecosystems, they do not consider situations when the system already is significantly disturbed by other significant stressors, such as overgrazing by sea urchins. As severe overgrazing of the kelp forests persists in northern Norway, the remaining patches of kelp and seaweed are most likely critically important for seeding the re-coloniisation of kelp and seaweed beds whenever the conditions become right for the system to shift back to the algae dominated state. A worst-case scenario would be when a major oil spill event destroyed the few remaining seaweed/kelp patches that have managed to survive outside the reach of the sea urchins. Several recent studies have pointed to the relevance of combined effect scenarios (see O'Gorman et al. 2012; Beyer et al. 2014). In the context of northern Norway, it is our view that sea urchin overgrazing and coastal oil spill events may represent a powerful stressor combination and should thus receive our close attention, especially in planning oil spill response action.

In the present study, we developed a kelp distribution model, and studied fauna distribution and dispersal in the Hammerfest area of Arctic Norway. The aim was to assess the vulnerability of coastal rocky shores to the combined effect from sea urchin overgrazing and oil spills. We have (1) modelled the distribution of healthy kelp forests in a sea urchin-grazed area (2) studied the fauna composition in kelp forests, sea urchin barrens and rocky shore seaweed communities (along wave exposure gradients for kelp) and (3) studied the dispersal of the organisms as an indicator of ecosystem recovery potential. Based on the obtained results and literature data we have assessed the vulnerability to oil spills for sheltered, moderately exposed and exposed rocky shores, and developed a hazard map that highlights the areas at different levels of vulnerability given the situation that a major oil slick makes landfall in the area. The potential use of this type of hazard map in planning and implementation of oil spill response operations is discussed.

\section{Methods}

\section{Study area}

The study area close to the city of Hammerfest (Finnmark county, Arctic Norway, Fig. 1) is characterised by a harsh climate, an outer coast exposed to wind and waves from the Barents Sea and an inner coast with large islands, rocky coasts, and deep fjords. Petroleum industrial activity in the area is related to two offshore fields in production and to the large LNG (liquified natural gas) plant and terminal located at the small island Melkøya just outside the city. There are no experiences with oil spills in this area, then we have sampled a quite large area where oil spill accidents possibly can happen in the future for evaluation of vulnerability.

\section{Field sampling of data on kelp coverage}

Data on kelp coverage were collected at 453 stations (Fig. 1) using underwater camera and GPS (accuracy $\pm 2 \mathrm{~m}$ ) on rocky seabed habitats in September 2008. The stations covered different wave exposure levels and terrain structures (such as slope and terrain curvature) typical for this part of the coast, and we surveyed down to 20-m depth. Laminaria hyperborea kelp c overage was recorded semi-quantitatively into one of four classes $(0=$ no kelp, $1=$ single plants or scarce occurrences (i.e. few individuals), $2=$ moderately dense (i.e. i.e. many plants, but not a completely dense canopy cover) or $3=$ dominating/dense, i.e. a completely dense canopy cover). On the stations with no kelps, we recorded 
Fig. 1 Map of the study area (within the square on the European-scaled map) and the stations at which data on coverage of kelp (Laminaria hyperborea) forests and sea urchin (Strongylocentrotus droebachiensis)dominated barren grounds were collected ( $n=453$, white dots), together with data on fauna composition as collected in kelp forests, seaweed communities and sea urchin (Strongylocentrotus droebachiensis)-grazed gravel areas, $n=11$, red dots. Some station may be hidden behind others. The overview map shows gebco.net elevation and depth, and the detailed map shows satellite images and bathymetry from geonorge. no. The dark blue area on the detailed map is due to lack of depth data

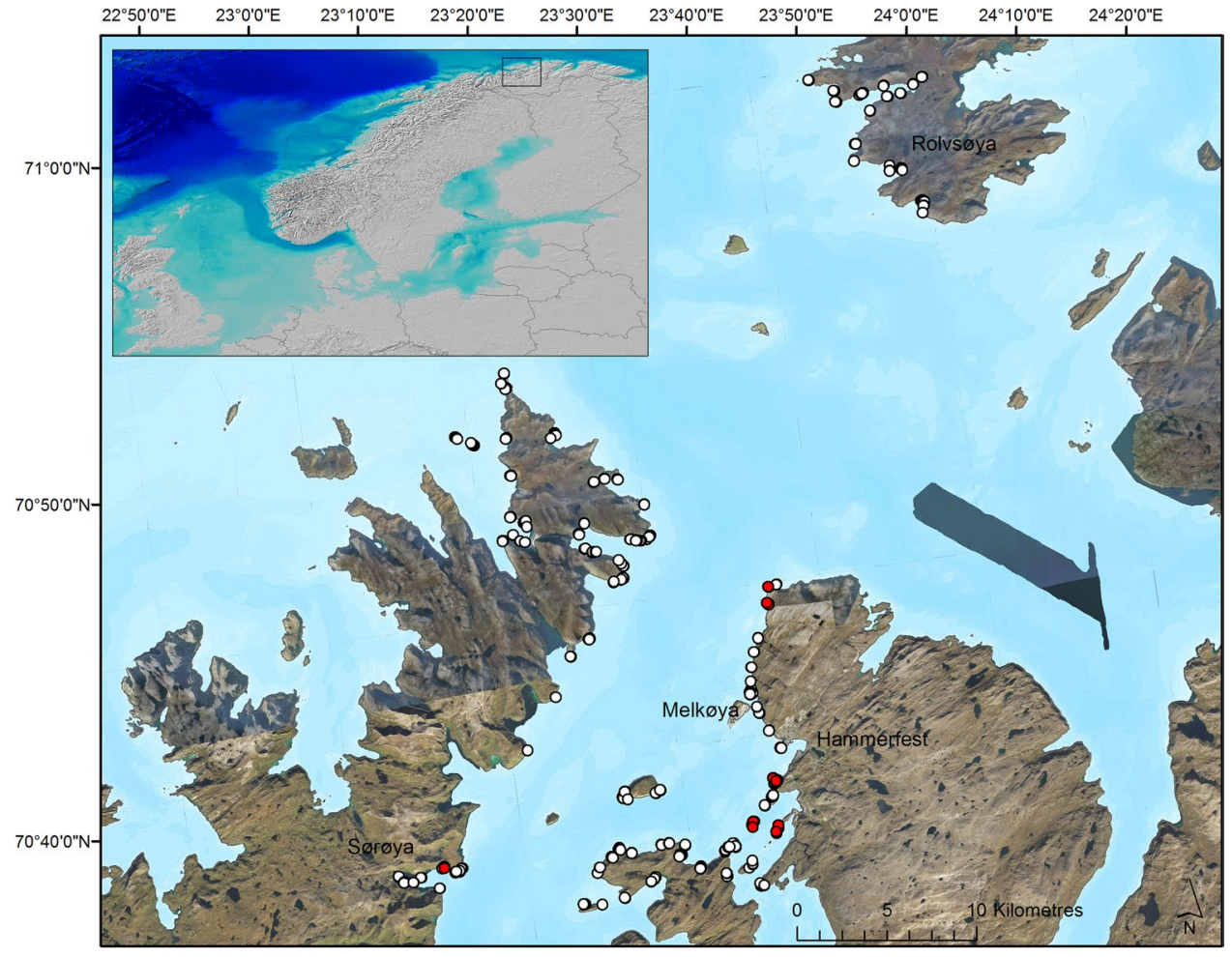

high densities of green sea urchins (Strongylocentrotus droebachiensis), as later confirmed by Fagerli et al. (2015).

\section{Field sampling of community composition and fauna mobility in kelp forests, seaweeds communities and sea urchin-grazed areas}

Fauna was collected by diving or snorkelling in both kelp forests and seaweed communities on rocky intertidal shores. Sampling was carried out in late summer (September 2008) and spring (April 2009). Epifauna associated with kelp ( $L$. hyperborea) was sampled at three exposed and three moderately exposed stations, at 3-5 m depth. Kelp stipes and holdfasts were sampled separately, three replicates of each kelp part from each station, altogether 72 samples. The laminas were not sampled as they have been found to house less fauna, and the species are found to be similar to those found on the stipe (Christie et al. 2003). Seaweed-associated fauna on rocky shores was sampled at low tide at three moderately exposed stations, three replicates of Fucacean plants at each station, 27 samples in total (the exposed areas were too rough for seaweed and were dominated by barnacles). The tidal range was about $2.5 \mathrm{~m}$ and the rocky intertidal shores were covered with extensive macroalgal (Fucacean) beds not grazed by sea urchins.

To test possible alternative sources for fauna that could disperse to seaweeds, the only available three-dimensional subtidal habitat in sea urchin-grazed areas was the aggregate of coarse gravel/pebbles (Wentworth scale, https://en.wikip edia.org/wiki/Grain_size, see also Waage-Nielsen et al. 2003), and this habitat was sampled for fauna analysis. Only two locations with this habitat were found in the shallow sublittoral zone. At these two stations, three replicates of gravel/pebbles (herby called gravel) with fauna were sampled within a $20 \times 20 \mathrm{~cm}$ frame, 12 samples in total. The frame size was approximately similar to the area of a kelp holdfast (see Christie et al. 2003).

Fauna traps (made as a bundle of $3 \times 1 \mathrm{~m}$ sisal rope, ca $200 \mathrm{ml}$ displacement volume, tested earlier to act as an artificial seaweed, see Norderhaug et al. 2007; Christie et al. 2009) were placed on the sea floor (tied to chains) in September 2008 to study colonisation rates of mobile animals to kelp forest and seaweed communities (typically crustaceans, polychaetes and molluscs). Three replicate traps were placed on the six subtidal kelp sites (three exposed and three moderately exposed stations) and on the three intertidal (moderately exposed) seaweed sites -in total 27 traps. The traps were collected after two days.

Each replicate of kelp stipe with epiphytes, kelp holdfast, whole Fucacean plants, gravel and fauna traps were sealed individually in a fine-meshed bag in situ. The samples were washed and sieved through a $250-\mu \mathrm{m}$ sieve and the fauna preserved. Habitat size of seaweed was quantified by displacement volume or weight measurements ( $\mathrm{ml}$ displacement $=$ gramme wet weight algae). Kelp stipe length was measured, and the biomass of the stipe associated epiphytic 
algae (the most important habitat for fauna, Christie et al. 2003) was measured. The fauna was identified to species or lowest taxonomic level possible, focusing on mobile fauna (Norderhaug et al. 2002; Jørgensen \& Christie 2003; Christie et al. 2009).

\section{Statistical analyses and distribution modelling}

Community analyses, distribution modelling, models of wave exposure and an assessment of probable oil spill effects is in this study used to classify the rocky intertidal shore in these sea urchin-dominated high north areas into vulnerability classes. As kelp forests may function as a source during the recovery of seaweed (Fucacean) communities on rocky shores, the distribution of kelp forests was modelled using depth (provided by the Hydrographic Service of Norway), slope, terrain curvature, light exposure, and wave exposure (as described in Bekkby et al. 2009). Wave exposure was modelled using data on fetch (distance to nearest shore, island, or coast), wind speed and wind frequency (i.e. the length of time that the wind came from different directions, details in Isæus (2004)). Data on wind speed and direction were provided by the Norwegian Meteorological Institute and averaged over 10 years (1995-2004). The model has been applied in several projects in Norway (e.g. Norderhaug et al. 2012; Pedersen et al. 2012; Bekkby et al. 2014; Rinde et al. 2014), Sweden (e.g. Eriksson et al. 2004), Finland (Isæus and Rygg 2005), the Danish region of the Skagerrak coast and the Russian, Latvian, Estonian, Lithuanian and German areas of the Baltic Sea (Wijkmark and Isæus 2010). All models had a spatial resolution of $25 \mathrm{~m}$. An ocean current model (including tidal driven currents) was not available for us at the time of the modelling.

For the spatial distribution modelling, moderately dense occurrences and sites completely dominated by kelp were used as presences (i.e. coverage class 2 and 3, $n=110$ ), absences, single individuals and scarce occurrences were used as absences (coverage class 0 and $1, n=343$ ). Data on kelp forest presence and absence were integrated in GIS together with the layers on the environmental factors. We analysed the statistical influence of depth, slope, terrain curvature, light exposure, wave exposure and latitude on kelp forest presence and absence using Generalized Additive Models (GAMs, Hastie and Tibshirani 1990, 2 degrees of freedom for the smoothing spline function) in S-PLUS 2000 and Akaike Information Criterion (the AICc calculations, as recommended by Burnham and Anderson 2004) for model selection. Based on the response curves from the GAM analysis, models on the predicted probability of distribution was developed at a spatial resolution of $25 \mathrm{~m}$. For model validation, assessing the model fit to the data, we used a five-fold cross-validation ROC test (Fielding and Bell 1997).
We compared the modelled probabilities (arcsine-transformed) for the kelp coverage classes observed in the field $(0=$ no kelp, $1=$ single plants, $2=$ medium dense, $3=$ dominating/dense) using ANOVA and a Multiple Range Tests in StatGraphics Plus 5.1.

We identified areas of seaweed on rocky shores using rule based GIS-layers on bathymetry, slope and wave exposure. Coastal rocky seaweed communities are found in the littoral zone (here defined from the lower astronomical tide level, which is the nautical chart 0 , to $+2 \mathrm{~m}$ ), on relatively steep slopes $\left(>7^{\circ}\right)$ in sheltered (the Isæus 2004, Simplified Wave Model (SWM $\leq 100,000)$ and moderately exposed $(\mathrm{SWM}>100,000$ and $\leq 500,000)$ areas.

To describe differences and similarities in faunal species compositions between habitats, non-metric Multi-Dimensional Scaling (MDS) based on Bray-Curtis similarity was performed in the PRIMER 6.0 computer package (Clarke 1993). Two-way crossed SIMPER with wave exposure level and season as factors was used to identify the species responsible for similarity within and dissimilarity between stations of different exposure level. 3-way Permutational ANOVA (PERMANOVA) was performed (Anderson 2001) to analyse community composition patterns between samples. Data were standardised so that each habitat counted equally in the analysis. In the PERMANOVA analysis, habitats (seaweed, kelp stipes, kelp holdfast, gravel), wave exposure level (moderately exposed, exposed) and season (spring, autumn) were used as fixed factors and station as random factor.

\section{Results}

\section{Kelp forest distribution}

The L. hyperborea kelp distribution model is a crucial part of the assessment of probable oil spill effects in this study, as the kelp forests may function as a source during the recovery. The probability of finding kelp forests was highest at wave exposed and shallow shoals (Fig. 2), see Online Resource 1, Fig. ESM1. Wave exposure was the single most important factor $(\mathrm{AUC}=0.84)$, followed by, in decreasing order, latitude, depth and terrain curvature (the latter with a 500-m calculation window). Including light exposure did not improve the model (Online Resource 1, Table ESM1) within this study area. Linking the modelled probability of finding kelp forests and the field recorded coverage of kelp $\left(p<0.0001, \mathrm{~F}_{3}=117.20\right.$, Online Resource 1, Fig. ESM2 $)$ showed (through the multiple range test) that the stations without kelp (coverage class 0) was different from all the other stations and that stations with single plants and scarce occurrences (coverage 1) was different from those dominated by kelp (coverage class 3 ). No difference was found 
Fig. 2 The modelled probability of kelp (Laminaria hyperborea) forest, based on the response curves shown in Online Resource 1, Fig. ESM1. The model is clipped to cover coastal waters only (i.e. within 1 nautical mile outside the base line) and include only the probabilities $>0.1$ (which are the moderately dense and dense forests according to Online Resource 1, Fig. ESM 2). The elevation and depth map is from gebco.net

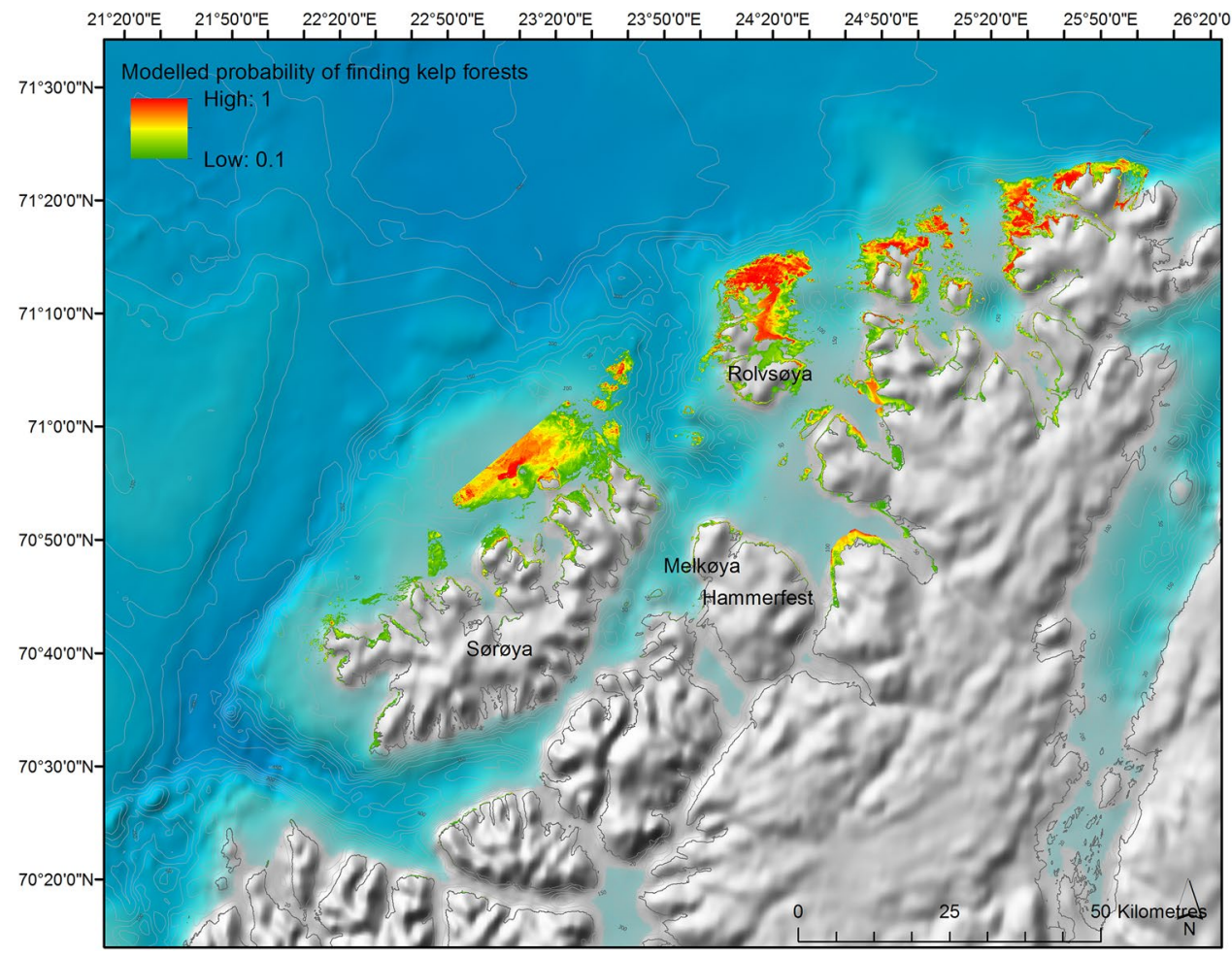

between stations with single plants (class 1) and medium dense forest (class 2).

\section{Fauna community composition}

The fauna community composition found in the different habitats will impact the recolonisation potential in the seaweed communities on rocky shores, as habitats with similar species composition will be able to function as a source during the recovery. A total of 83977 individuals, belonging to
265 taxa were identified in the fauna samples from subtidal kelps, intertidal seaweeds, sea urchin-grazed gravel/pebble habitats and traps ("artificial seaweed"). The major faunal groups were polychaetes, gastropods, amphipods, isopods and bivalves (see species list in Online Resource 2). Statistics are presented in Table 1. The healthy kelp forests (stipe, epiphytes and holdfast) had more fauna species and a higher fauna density per sample than the other habitats, particularly on the exposed sites (Fig. 3). The difference between grazed and less-grazed areas is most profound when it comes to

Table 1 Results from the Permutational ANOVA (PERMANOVA) analysis on fauna communities on Laminaria hyperborea kelp (stipes and holdfast) in healthy forests, seaweed communities and sea urchin (Strongylocentrotus droebachiensis)-grazed gravel areas

\begin{tabular}{|c|c|c|c|c|c|c|c|c|c|c|c|c|c|c|c|}
\hline \multirow[t]{2}{*}{ Variable } & \multicolumn{5}{|c|}{ Stipes vs seaweed } & \multicolumn{5}{|c|}{ Holdfast vs seaweed } & \multicolumn{5}{|c|}{ Gravel vs seaweed } \\
\hline & $d f$ & SS & MS & Pseudo- $F$ & $P$ value & $d f$ & SS & MS & Pseudo- $F$ & $p$ value & $d f$ & SS & MS & Pseudo- $F$ & $p$ \\
\hline Substrate (Su) & 1 & 23,207 & 23,207 & 17.4 & 0.001 & 1 & 33,071 & 33,071 & 34.8 & 0.01 & 1 & 16,057 & 16,057 & 7.2 & 0.001 \\
\hline Season (Se) & 1 & 16,619 & 16,619 & 12.5 & 0.001 & 1 & 12,155 & 12,155 & 12.7 & 0.01 & 1 & 13,464 & 13,464 & 6.0 & 0.001 \\
\hline Station $(\mathrm{St})$ & 2 & 8713.9 & 4357 & 3.2 & 0.001 & 2 & 7752.7 & 3876.4 & 4.0 & 0.01 & 3 & 20,325 & 6774.9 & 3.0 & 0.001 \\
\hline $\mathrm{Su}-\mathrm{Se}$ & 1 & 11,292 & 11,292 & 8.4 & 0.001 & 1 & 9543.8 & 9543.8 & 10.0 & 0.01 & - & - & - & - & - \\
\hline $\mathrm{Su}-\mathrm{St}$ & 2 & 9977 & 4988.5 & 3.7 & 0.001 & 2 & 6938.3 & 3469.2 & 3.6 & 0.01 & - & - & - & - & - \\
\hline $\mathrm{Se}-\mathrm{St}$ & 2 & 9645.5 & 4822.7 & 3.6 & 0.001 & 2 & 7461.8 & 3730.9 & 3.9 & 0.01 & - & - & - & - & - \\
\hline Su-Se-St & 2 & 9235 & 4617.5 & 3.4 & 0.001 & 2 & 9646.9 & 4823.4 & 5.0 & - & - & - & - & - & - \\
\hline
\end{tabular}

The table shows the variables substrate ( $\mathrm{Su}$ ), sampling season ( $\mathrm{Se}$ ), station (St, random factor) and their interactions, the degrees of freedom (Df), sum of squares (SS), mean square (MS), Pseudo-F (a test statistic based on multivariate analogues to expected mean squares) and $p$ values by permutation for differences between kelp stipes and seaweed samples, kelp holdfasts and seaweed samples and between gravel and seaweed samples

In some cases, interactions could not be included in the analysis because of too few $\mathrm{df}$ 

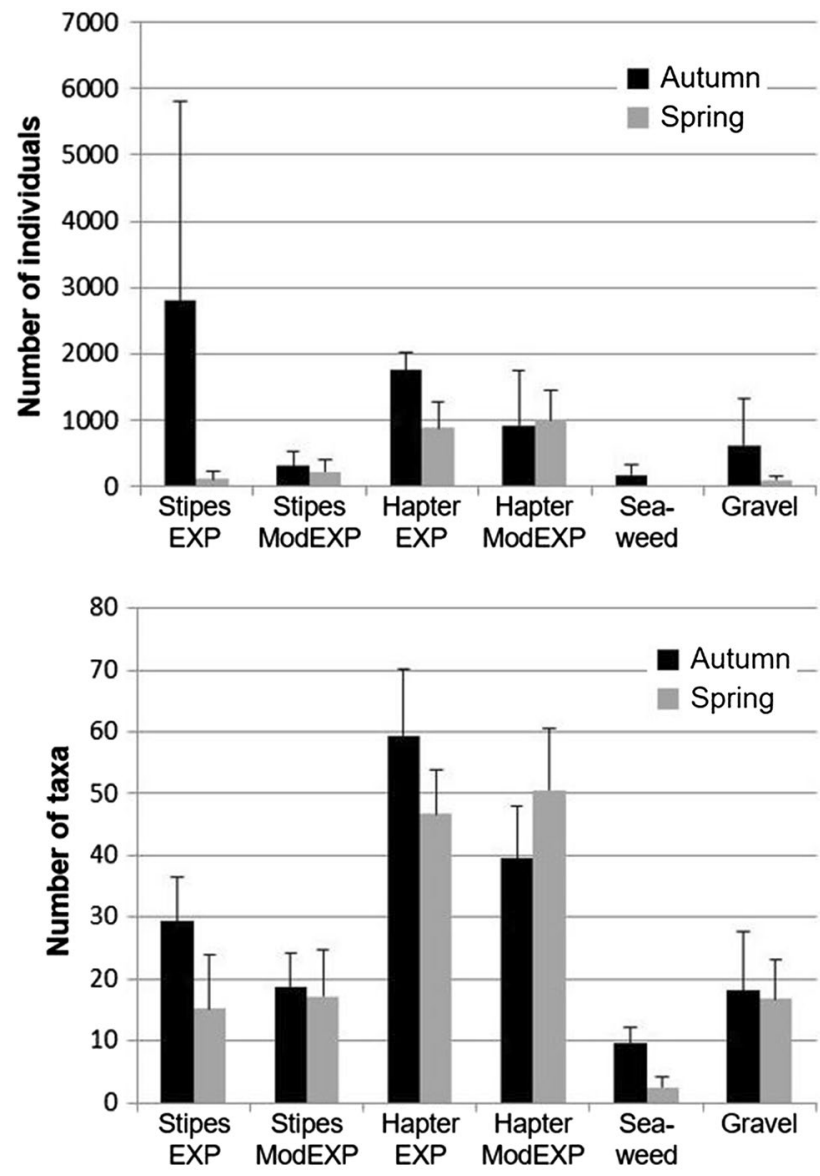

Fig. 3 Number of individuals (top) and species/taxa (bottom) per sample from Laminaria hyperborea kelp (stipes and holdfast/hapteron) in healthy forests, seaweed communities and sea urchin (Strongylocentrotus droebachiensis)-grazed gravel areas in autumn and spring. EXP: exposed stations, ModEXP: moderately exposed stations. Seaweed and gravel were found at moderately exposed stations only. $N=3$ for all kelp parts and seaweed, $n=2$ for gravel

number of individuals related to stipe of the kelps in autumn. However, the epiphyte volumes in autumn at the two areas do not show this pattern ( $t$-test, $p=0.4, n=9$ for each area). The most species rich habitat was the holdfast of the kelp plants, in both seasons. Compared to both seaweed and sea urchin-grazed gravel areas, healthy kelp forests (both stipes and holdfast) stands out as the most diverse habitat. Number of species and individuals were significantly different, both among substrate (kelp/seaweed/gravel), season (spring/ autumn) and location (exposed/moderately exposed).

Similarities in presence of species between the different habitats analysed using SIMPER, revealed that $50 \%$ of species on Fucus spp. were found on kelp stipes, $65 \%$ in holdfasts, whereas $38 \%$ of species on seaweed are found in sublittoral gravel/pebbles. Statistics are shown in Table 2. Some species in seaweed, such as Littorina littorea and Idotea emerginata, were not found on kelp (stipes or holdfasts) or
Table 2 Results from the SIMPER analysis on the fauna communities, showing the average dissimilarity between the seaweed communities and healthy Laminaria hyperborea kelp forests (stipe and holdfast) and sea urchin (Strongylocentrotus droebachiensis)-grazed gravel communities, respectively

\begin{tabular}{llll}
\hline Group & Seaweed vs stipes & $\begin{array}{l}\text { Seaweed } \\
\text { vs holdfast }\end{array}$ & $\begin{array}{l}\text { Seaweed } \\
\text { vs gravel }\end{array}$ \\
\hline Average dissimilarity & 90.05 & 90.31 & 96.66 \\
Total no. species & $99 / 40$ & $149 / 40$ & $81 / 40$ \\
No. of exclusive species & $79 / 20$ & $123 / 14$ & $66 / 25$ \\
\hline
\end{tabular}

The number of species (taxa) found exclusively in one substrate is also shown

in gravel. The amphipod families Ishyroceridae and Stenothoidae, along with predatory polychaetes (Pholoe sp., Polynoidae, Syllidae and Nereis pelagica) were abundant in exposed areas. The caprellid amphipods Caprella linearis/septentrionalis had higher abundances in the moderately exposed areas than exposed areas, along with juvenile gastropods, the bivalve Hiatella arctica and the amphipod Gammarellus homari. Also, juvenile S. droebachiensis were more common in kelp holdfasts in moderately exposed areas.

\section{Colonisation of mobile fauna (colonisation rates in traps)}

The colonisation ability of mobile fauna found in habitats with similar community composition will impact the recolonisation potential in the seaweed communities on rocky shores. There were small but significant differences between fauna colonising the fauna traps in the outer (exposed) and inner (moderately exposed) areas (Table 3, $p=0.001$, Pseudo- $\left.F_{1,27}=15.74\right)$. The number of species in the traps did not vary much between exposed and moderately exposed areas or between the littoral and sublittoral (about an average of 10 species per trap), but the number of individuals varied significantly (at a magnitude between 50 and 500 per trap). However, the significant difference in fauna mobility was not

Table 3 Results from the Permutational ANOVA (PERMANOVA) analysis of the fauna traps ("artificial seaweed"), analysing differences in colonisation rates of mobile animals between stations (fixed, 6 levels) sampled from inner (moderately exposed) and outer (exposed) coast (fixed, 2 levels)

\begin{tabular}{llllll}
\hline Source & $d f$ & SS & MS & Pseudo- $F$ & $p$ \\
\hline Coast (inner/outer) & 1 & 11,593 & 11,593 & 15.74 & 0.001 \\
Station & 4 & 7637.1 & 1909.3 & 2.5924 & 0.001
\end{tabular}

The table shows the degrees of freedom (df), sum of squares (SS), mean square $(M S)$, Pseudo- $F$ (a test statistic based on multivariate analogues to expected mean squares) and $p$ values by permutation for differences 
related to the number of species, but to which species that colonised the traps. In exposed areas, more mobile amphipods (Ischyroceridae, Stenothoidae) were colonising the traps, whereas the juvenile gastropods were colonising the traps in moderately exposed areas. The differences between fauna composition is shown in Fig. 4. The fauna composition in the traps was most close to fauna in kelps, and different from the fauna in gravel and seaweed, as shown in Fig. 4. This indicate a higher ability of colonisation by subtidal than intertidal fauna.

\section{Discussion}

\section{Assessing the vulnerability of Arctic rocky shore ecosystems}

This study discusses the relevance of taking spatial dimension of stressor interactions into account when assessing vulnerability of coastal ecosystems to human activities. In the study area at the northernmost part of the Norwegian coast, we found differences in fauna composition, colonisation rates of mobile animals and distribution of kelp forests along environmental gradients in a way that is relevant for assessing oil spill vulnerability. The assessments based on our results are comparable to what has been outlined by Gundlach and Hayes (1978). These northernmost areas of the Norwegian coast showed distribution patterns of healthy kelp forests that was comparable to what was found in other studies (Rinde et al. 2014), i.e. that the kelp forest is found at the outer exposed coast in sea urchin-grazed areas. We found both the kelp forests and the intertidal seaweed communities to house a rich fauna, similar to what has been found further south (Christie et al. 2009), and which has also been shown by studies from even further north (Lippert et al. 2001; Hop et al. 2002). The fauna trap colonisation study showed high ability of subtidal and kelp forest associated fauna to disperse and colonise new habitats, while the intertidal seaweed-associated fauna had a more limited colonisation rate.

In the event of oil shoring, the littoral zone and to some extent the shallow part of the sublittoral zone will be most heavily exposed (Crowe et al. 2000). Studies of oil spills in both the high north (Peterson et al. 2003) and far south (Simpson et al. 1995) show that seaweeds and associated invertebrate communities are affected, both through acute toxic effects, long term effects (such as continuous exposure to stranded oil, Gundlach and Hayes 1978) and as cascade effects through trophic interactions (Peterson et al. 2003), affecting for instance associated fish populations (Incardona et al. 2015). The consequences depend on the type of oil, the environmental conditions at the site (such as depth, substrate, and wave exposure), the type of ecosystem that is hit, season and the countermeasure strategies used (see Alves et al. 2014). Oil will persist for a longer time when hitting soft bottom areas compared to rocky shores and will be washed away more rapidly in exposed than in sheltered areas (Gundlach and Hayes 1978). In seaweed beds in the more sheltered intertidal, the oil may persist inside dense vegetation structures (Smith and Simpson 1993; Simpson et al. 1995). The oil will be particularly harmful to sensitive organisms of the intertidal, such as crustaceans, molluscs

Fig. 4 Multi-Dimensional Scaling (MDS) plot of the fauna composition on stipes and holdfasts of kelp (Laminaria hyperborea) in healthy forests, rocky intertidal seaweed communities, sea urchin (Strongylocentrotus droebachiensis)-grazed gravel areas and the artificial fauna traps. $2 D$ Stress: 0.17

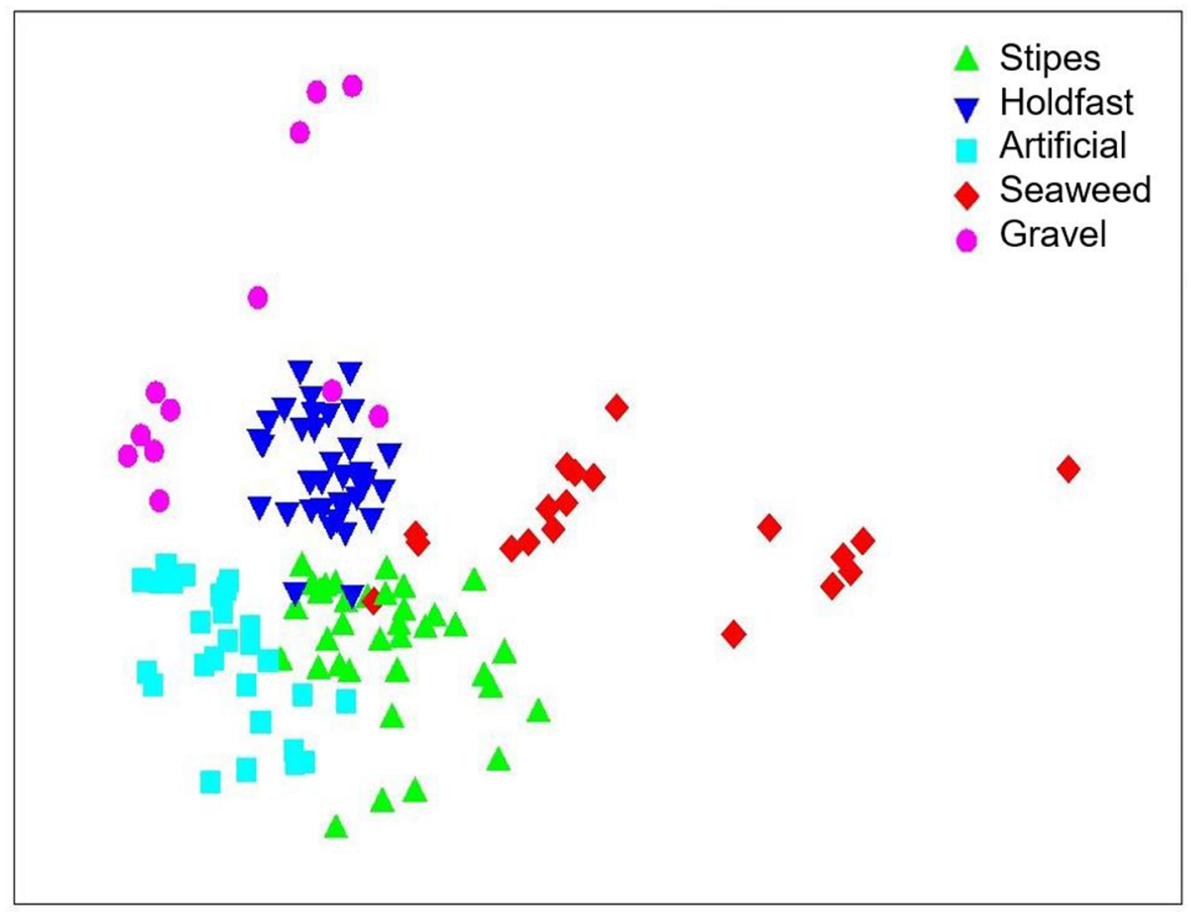


and polychaetes (as described by e.g. Nikitik and Robinson 2003; Alves et al. 2014). Some of the crustaceans (Bonsdorff et al. 1990; Nikitik and Robinson 2003) and grazing molluscs (see Crowe et al. 2000) are found to be particularly sensitive to oil, and preliminary results shows that periwinkles (genus Littorina) along the rocky shores of the Barents Sea are highly sensitive to pollution (Maltseva pers. comm.). These animals live in high densities in intertidal seaweed communities in our study area (also found by Christie et al. 2009) and have an important ecological function in the transfer of benthic primary production to higher levels in the food web (Norderhaug et al. 2005). The sea urchins itself have vide spatial distribution and high reproduction rate (Fagerli et al. 2015) and will probably not be affected by oil to a level that allow kelp recovery (se also Ling et al. 2015). Our study therefore implies increased vulnerability in more sheltered areas due to the lack of the source habitat needed (i.e. the kelp forest) to recolonise affected areas.

Kelp has a limited spatial dispersal (Fredriksen et al. 1995) but high turnover (Pedersen et al. 2012), and the associated fauna has high dispersal potential (Jørgensen and Christie 2003; Christie et al. 2009). Hence, even though oil may be physically dispersed and affect the outer kelp forests, and although kelp holdfasts can store oil and thereby affect fauna over time (Smith and Simpson 1993; Simpson et al. 1995), the continuous beds of horizontal and vertical (depth) distributed kelp forests are a large source for colonisation and restoration of the kelp itself and of the kelp-associated fauna along these exposed coastlines. The fauna communities associated to intertidal seaweeds were different from the other habitats (Fig. 4). The analysis of similarities in the presence of species revealed that $50 \%$ of species on Fucacean species are also found on kelp stipes, $65 \%$ in holdfasts. This implies that the kelp forests, if intact, may function as a source for recolonisation of rocky shore communities after an oil spill. Based on community analyses, distribution modelling and the above-discussed assessment of probable oil spill effects, we classified the rocky intertidal shore in these high north areas into vulnerability classes (Table 4). Vulnerability was divided into low, moderate and high, as also shown on a rocky intertidal shores hazard map (Fig. 5). In the sheltered and moderately exposed areas in which the sea urchins have grazed all of the kelp forests, the rocky intertidal seaweed communities will not have any kelp forests or other habitats as a nearby source for recolonisation, and these rocky shore areas will therefore take a long time to recover after an oil spill. As a consequence, these areas have high vulnerability. The vulnerability may be large for all fauna groups and even the seaweeds may be heavily harmed (see Peterson et al. 2003). In these sheltered and moderately exposed areas, we might find some shallow patches of kelp forests, even though green sea urchins have grazed down most of the areas. These areas will have medium vulnerability, as the remaining kelp patches will function as a source for recolonisation, but may be harmed if oil is submerged, particularly if oil enters the holdfasts (Smith and Simpson 1993; Simpson et al. 1995). In the wave-exposed areas, we have no or little seaweed on the rocky intertidal but extensive kelp forests in the sublittoral. If fauna is affected, the high turnover and the high dispersal and colonisation will most likely result in a rapid recovery of most species (based on: Norderhaug et al. 2002; Jørgensen and Christie 2003; WaageNielsen et al. 2003; Christie et al. 2007, 2009; Pedersen et al. 2012). These areas therefore have low vulnerability. The high vulnerability areas covered $50.2 \%$ of the seaweed rocky shores in the area, medium vulnerable areas covered $39.3 \%$ and low vulnerable areas covered $10.5 \%$.

We had no ocean current model (including tidal driven currents) at the time of the modelling. Current speed is important for the drift of oil spills and the recolonisation potential of seaweed-associated fauna, the latter because of the ocean current driven movement of the planktonic life
Table 4 The modelled intertidal seaweed communities on rocky shores classified according to the vulnerability, as outlined in the text

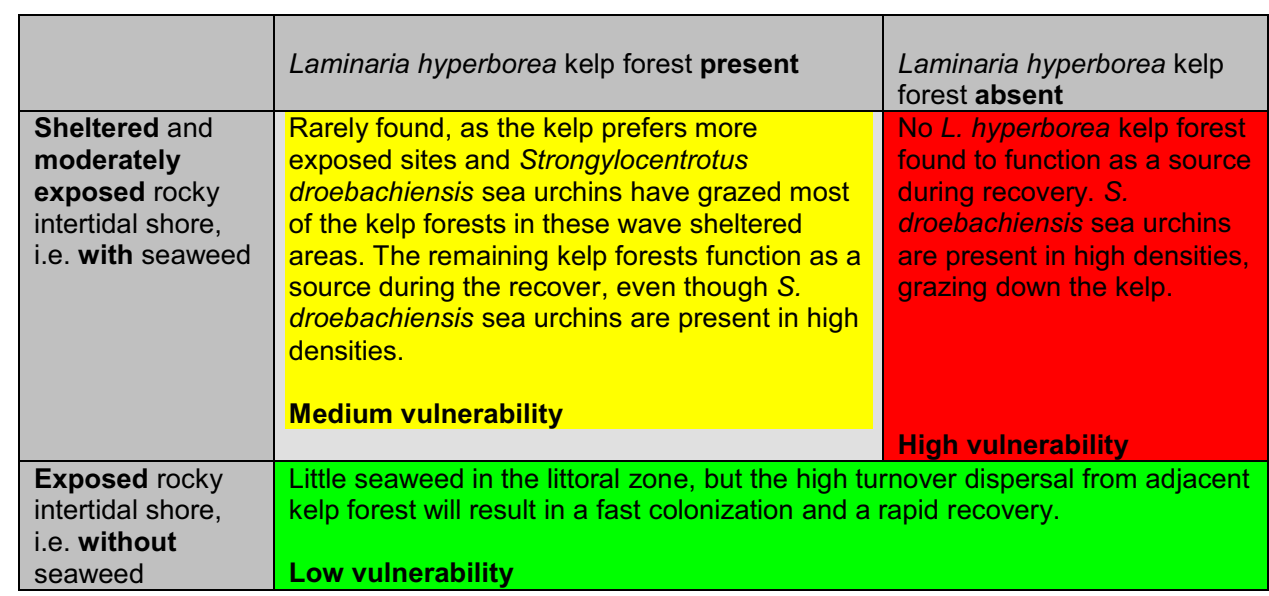

Red: highly vulnerable, yellow: medium vulnerable, green: low vulnerability 
Fig. 5 The modelled intertidal rocky shores classified according to the vulnerability as defined in Table 4. Red: highly vulnerable, yellow: medium vulnerable, green: low vulnerability. The coastline has been thickened in order to make it more visible at the scale of this map. The elevation and depth map is from gebco.net

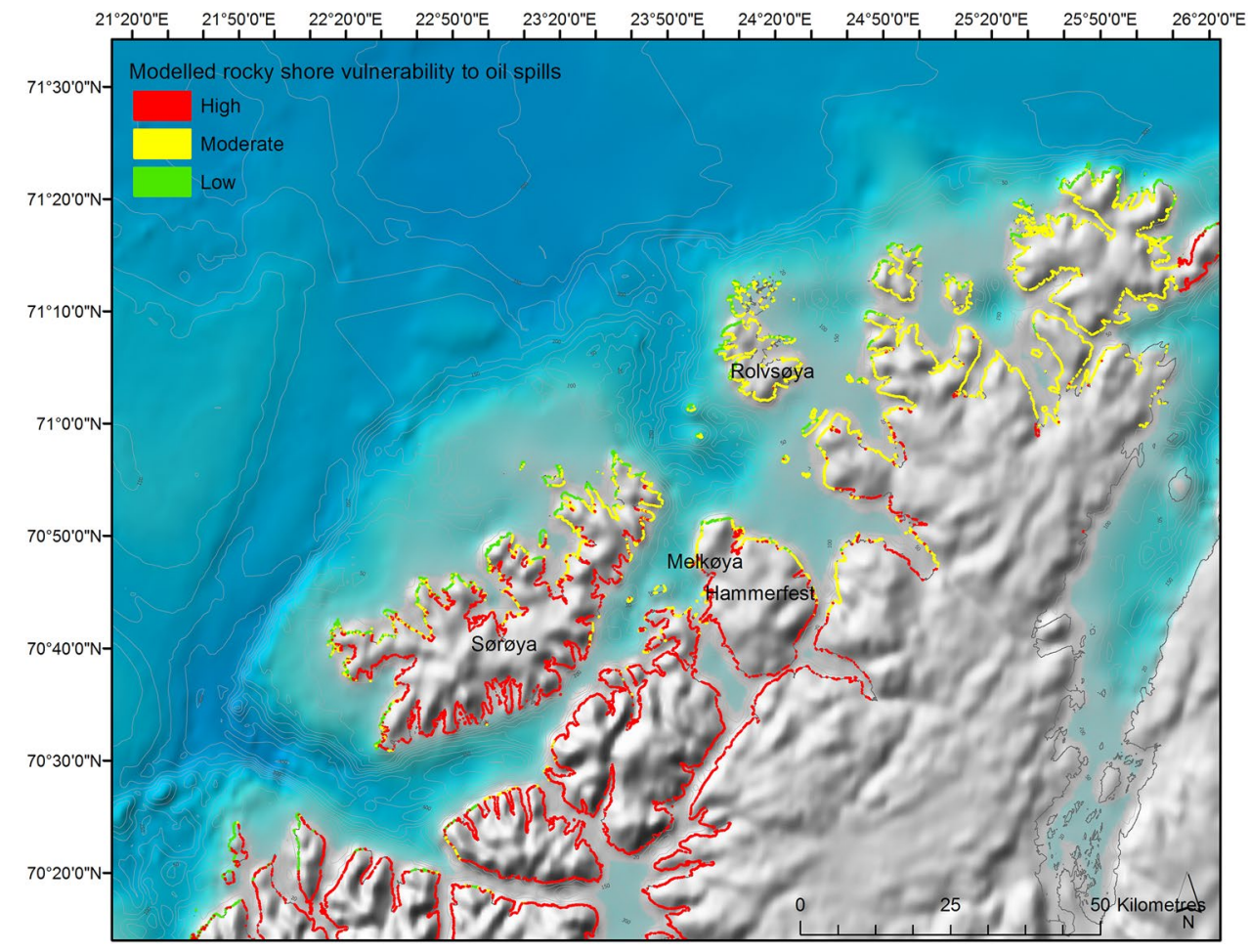

stages. Including model on ocean currents would greatly improve the assessment of vulnerability of areas. However, such models were not available.

\section{Ecological effects of marine oil spills in Arctic coastlines}

Understanding the fate and effects of major oil spills is difficult, as multiple and dynamic factors related to the spill situation, environmental conditions, and the response operation will influence the behaviour of the spill and the type and scale of the impacts. Knowledge is available from several publications, many of which concern particularly serious events such as the Exxon Valdez oil spill (EVOS) in 1989 and the Deepwater Horizon oil spill (DWHOS) in 2010 (Peterson et al. 2003; Atlas and Hazen 2011; Beyer et al. 2016). Regarding the Arctic, the knowledge base on oil spills and their impacts is more limited, i.e. apart from EVOS. A comprehensive summary on environmental impacts of Arctic oil spills and Arctic spill response technologies was recently collected by Word et al. (2014), highlighting the many challenges and knowledge gaps that exist on these matters. Situations when the ecosystem and certain important keystone species already is under a severe pressure from other drivers and stressors, e.g. overgrazing from sea urchins, may call for extra carefulness about not further adding to the stress. Habitat building macroalgal species, like kelp, are key ecosystem along most of the Norwegian coast, although many and large areas have been in a poor state for decades due to sea urchin overgrazing (Norderhaug and Christie 2009). In the area addressed by this study, $>20$ sea urchins have at the most been observed per $\mathrm{m}^{2}$ (Norderhaug and Christie 2009). However, even in the strongly overgrazed areas we found remaining patches of intact kelp forests, and these are likely to be important for the ability of the system to rapidly return to a kelp-dominated state when the conditions are right. Based on the present study, we suggest that measures/operations applied during oil spill response actions along sea urchin overgrazed Arctic coasts should pay extra attention to protecting these remaining patches of kelp and other seaweeds. The operative decisions that are taken by the spill response managers could be where and when to establish passive measure such as floating oil barriers and where and when to use, or avoid using, active measures such as oil-burning, chemical oil dispersing agents and shoreline clean-up operations. When considering these issues in forehand, the preparation of spatial risk maps, as suggested herein, may serve as important tools to facilitate the planning, preparation, and training of spill responses along vulnerable Arctic coastlines as well as optimal decision making during the execution of such actions.

\section{Implications for oil spill management}

Regarding oil spill preparedness, the environmental legislation of Norway requires that preparations are made for minimising all relevant risks and for establishing response systems that can deal with all relevant events. The Norwegian 
Coastal Administration, along with the operating companies in the offshore oil and gas sector and NOFO (Norwegian Clean Seas Association for Operating Companies), are central players in the national oil spill contingency activities, together with other national, municipal, and private stakeholders. Measures to minimise risks for oil spills at offshore facilities and technical systems for mechanical recovery of oil at sea have been the two most important focuses. A key aim in oil spill responses is to minimise the amount of oil that reaches the shoreline. However, still oil spill response operations must be planned. This study implies that the presence of one pressure (such as sea urchin grazing) may influence on the vulnerability from another (such as an oil spill) and highlights the importance of assessing multiple pressures when planning coastal oil spill response operations. The kelp forests in Arctic Norway are highly productive and the seaweed communities host large colonies of sea birds and mammals. Our fauna community analyses, distribution modelling and classification visualise how the vulnerability to oil spills varies along the coast. This suggests that management and countermeasures should take into account local differences in turnover, dispersal and potential for recolonisation. This new type of advice for northern coast is valid for the hard bottom benthic and rocky shore areas (that is dominating habitat in the actual region), and other studies and models are needed to provide advice for sandy beaches or other habitats, resources, and areas. As kelp beds recover at some parts of the North Atlantic coast (Norderhaug and Christie 2009; Rinde et al. 2014), updated knowledge on temporal and spatial changes in ecosystem structure and function must have implication for alterations of management practices for coastlines for oil spill action plans. However, the situation with sea urchin grazing of kelp forests has been persistent for more than 40 years, extending all over Arctic Norway, into Russia, and north to Jan Mayen and Spitsbergen (see review by Norderhaug and Christie 2009), so the assumptions made here should be valid for a large area and also into the future. The evaluations made here have not been addressed earlier and may be implemented in the international and national oil spill response reports (Aspholm et al. 2005; IPIECA 2012). Also, the recent mapping of coastal habitats in Norway may provide data for making similar vulnerability models and maps for most of the Norwegian Arctic coast.

Acknowledgements This study is part of the Arctic Seas Biodiversity (ASBD) project, scientific project leader Sabine Cochrane (AkvaplanNIVA), and has received funding from Eni Norge; contract P289, 2008. The authors are grateful to Eni representatives Laura Bracco, Carlo Alberto Cova, Nora Hveding Hegseth, Erik Bjørnbom and Liv Nielsen, as well as Tim Reed, Fauna and Flora International, for their various roles in the project. The authors thank Janne Kim Gitmark (NIVA) for diving efforts during field work and the captains Roar Lorentsen and Lars-Bjørn Mehus for boat assistance. The authors wish to thank prof. Wim Vader for quality assurance of fauna identification, Andrey Sikorski for identification of polychaetes, Gunhild Garte Nervold, and Halldis Ringvold for assistance on fauna identification, and Paul Renaud (Akvaplan-NIVA) and Torgeir Bakke (Bakke Engineering) for their helpful comments on the manuscript.

\section{Compliance with ethical standards}

Conflict of interest There are no conflicts of interest related to field work environmental, ethics of safety standards, and no conflicts related to ASBD project or ENI as funding of the study

Open Access This article is distributed under the terms of the Creative Commons Attribution 4.0 International License (http://creativeco mmons.org/licenses/by/4.0/), which permits unrestricted use, distribution, and reproduction in any medium, provided you give appropriate credit to the original author(s) and the source, provide a link to the Creative Commons license, and indicate if changes were made.

\section{References}

Alves TM, Kokinou E, Zodiatis G (2014) A three-step model to assess shoreline and offshore susceptibility to oil spills: the south Aegean (Crete) as an analogue for confined marine basins. Mar Poll Bull 86:443-457

Anderson MJ (2001) A new method for non-parametric multivariate analysis of variance. Austr J Ecol 26:32-46

Aspholm OØ, Dragsund E, Skogen K, Brude OW (2005) Risikoindikatorer for helhetlig miljørisikoanalyse I Barenshavet. DNV Rapport 2005-0665 (https://www.regjeringen.no/globalassets/upload/kilde /md/rap/2005/0008/ddd/pdfv/251885-dnv_rapport_om_risikoindi katorer.pdf)

Atlas RM, Hazen TC (2011) Oil biodegradation and bioremediation: A tale of the two worst spills in U.S. history. Environ Sci Technol 45(16):6709-6715

Bambulyak A, Frantzen B, Rautio R (2015) Oil transport from Russian part of the Barents Region 2015 status report. The Norwegian Barents Secretariat and Akvaplan-niva, Norway, p 105

Bekkby T, Rinde E, Erikstad L, Bakkestuen V (2009) Spatial predictive distribution modelling of the kelp species Laminaria hyperborea. Est Coast Shelf Sci 66(10):2106-2115

Bekkby T, Rinde E, Gundersen H, Norderhaug KM, Gitmark J, Christie $\mathrm{H}$ (2014) Length, strength and water flow: relative importance of wave and current exposure on kelp Laminaria hyperborea morphology. Mar Ecol Prog Ser 506:61-70

Beyer J, Petersen K, Song Y, Ruus A, Grung M, Bakke T, Tollefsen KE (2014) Environmental risk assessment of combined effects in aquatic ecotoxicology: a discussion paper. Mar Environm Res 96:81-91

Beyer J, Trannum HC, Bakke T, Hodson PV, Collier TK (2016) Environmental effects of the Deepwater Horizon oil spill: a review. Mar Poll Bull 110(1):28-51

Bonsdorff E, Bakke T, Pedersen A (1990) Colonization of amphipods and polychaetes to sediments experimentally exposed to oil hydrocarbons. Mar Poll Bull 21:355-358

Boufadel MC, Bechtel RD, Weaver J (2006) The movement of oil under non-breaking waves. Mar Poll Bull 52:1056-1065

Burnham KP, Anderson DR (2004) Multimodel inference: understanding AIC and BIC in model selection. Sociol Met Res 33:261-304

Christie H, Jørgensen NM, Norderhaug KM, Waage-Nielsen E (2003) Species distribution and habitat exploitation of fauna associated with kelp (Laminaria hyperborea) along the Norwegian coast. J Mar Biol Ass UK 83:687-699 
Christie H, Jørgensen NM, Norderhaug KM (2007) Bushy or smooth, high or low; Importance of habitat architecture and vertical level for distribution of fauna on kelp. J Sea Res 58:198-208

Christie H, Norderhaug KM, Fredriksen S (2009) Macrophytes as habitat for fauna. Mar Ecol Prog Ser 396:221-233

Clarke KR (1993) Non-parametric multivariate analysis of changes in community structure. Aus J Ecol 18:117-143

Crowe TP, Thompson RC, Bray S, Hawkins SJ (2000) Impact of anthropogenic stress on rocky intertidal communities. J Aquat Ecosyst Stress Recov 7:273-297

Eriksson BK, Sandström A, Isæus M, Schreiber H, Karås P (2004) Effects of boating activities on aquatic vegetation in the Stockholm Archipelago, Baltic Sea. Estuar Coast Shelf Sci 61:339-349

Fagerli CW, Stadniczeñko SG, Pedersen MF, Christie H, Norderhaug KM (2015) Population dynamics of Strongylocentrotus droebachiensisin kelp forest and overgrazed areas in Norway. Mar Biol 162:1215-1226. https://doi.org/10.1007/s00227-015-2663-3

Fielding AH, Bell JF (1997) A review of methods for the assessment of prediction errors in conservation presence/absence models. Environm Conserv 24:38-46

Filbee-Dexter K, Scheibling RE (2014) Sea urchin barrens as alternative stable states of collapsed kelp ecosystems. Mar Ecol Prog Ser 495:1-25

Fredriksen S, Sjøtun K, Lein TE, Rueness J (1995) Spore dispersal in Laminaria hyperborea (Laminariales, Phaeophyceae). Sarsia 80:47-53

Gundlach ER, Hayes MO (1978) Vulnerability of coastal environments to oil spill impacts. Mar Tech Soc J 12:18-27

Hastie TJ, Tibshirani RJ (1990) Generalized Additive Models. Chapman and Hall, London, UK

Hop H, Pearson T, Hegseth EN et al (2002) The marine ecosystem of Kongsfjorden. Pol Res 21:167-208

Incardona JP, Carls MG, Holland L, Linbo TL, Baldwin DH, Myers KS, Peck KA, Tagal M, Rice SD, Scholz NL (2015) Very low embryonic crude oil exposures cause lasting cardiac defects in salmon and herring. Scie Rep 5:13499

IPIECA (2012) Sensitivity mapping for oil spill response. IOGP Report Number 477 (https://www.oilspillresponseproject.org/wp-content/ uploads/2017/01/Sensitivity_Mapping_2016.pdf

Isæus M (2004) Factors structuring Fucus communities at open and complex coastlines in the Baltic Sea. Dissertation, Botanical institute, Stockholm University, p 165

Isæus M, Rygg B (2005) Wave exposure calculations for the Finnish coast. NIVA report 5075. 24 p. ISBN; 82-577-4780-7

Jørgensen NM, Christie H (2003) Diurnal, horizontal and vertical dispersal of kelp-associated fauna. Hydrobiol 503:69-76

Li ZK, Lee K, King T, Boufadel MC, Venosa AD (2010) Effects of temperature and wave conditions on chemical dispersion efficacy of heavy fuel oil in an experimental flow-through wave tank. Mar Poll Bull 60:1550-1559

Ling SD, Scheibling RE, Rassweiler A, Johnson CR, Shears N, Connell SD, Salomon AK, Norderhaug KM, Perez-Matus A, Hernandez JC, Clemente S, Blamey LK, Hereu B, Ballesteros E, Sala E, Garrabou J, Cebrian E, Zabala M, Fujita D, Johnson LE (2015) Global regime shift dynamics of catastrophic sea urchin overgrazing. Phil Trans R Soc B Biol Sci 370

Lippert H, Iken K, Rachor E, Wiencke C (2001) Macrofauna associated with macroalgae in the Kongsfjord (Spitsbergen). Pol Biol 24:512-522

Nikitik CCS, Robinson AW (2003) Patterns in benthic populations in the Milford Haven waterway following the 'Sea Empress' oil spill with special reference to amphipods. Mar Pol Bull 46:1125-1141

Norderhaug KM, Christie H (2009) Sea urchin grazing and kelp revegetation in the NE Atlantic. Mar Biol Res 5:515-528
Norderhaug KM, Christie H, Rinde E (2002) Colonisation of kelp imitations by epiphyte and holdfast fauna; a study of mobility patterns. Mar Biol 141:965-973

Norderhaug KM, Christie H, Fosså JH, Fredriksen S (2005) Fishmacrofauna interactions in a kelp (Laminaria hyperborea) forest. J Mar Biol Ass UK 85:1279-1286

Norderhaug KM, Christie H, Fredriksen S (2007) Space limitation in a Norwegian kelp Laminaria hyperborea forest? Evidence from using artificial habitats. J Sea Res 58:120-124

Norderhaug KM, Christie H, Andersen GS, Bekkby T (2012) Does the diversity of kelp forest macrofauna increase with wave exposure? J Sea Res 69:36-42

O'Gorman EJ, Fitch JE, Crowe TP (2012) Multiple anthropogenic stressors and the structural properties of food webs. Ecology 93:441-448

Pedersen MF, Nejrup LB, Fredriksen S, Christie H, Norderhaug KM (2012) Effects of wave exposure on population structure, demography, biomass and productivity in kelp, Laminaria hyperborea. Mar Ecol Prog Ser 451:45-60

Peterson CH, Rice SD, Short JW, Esler D, Bodkin JL, Ballachey BE, Irons DB (2003) Long-term ecosystem response to the Exxon Valdez oil spill. Science 302(5653):2082-2086

Rinde E, Christie H, Fagerli CW, Bekkby T, Gundersen H, Norderhaug KM, Hjermann DØ (2014) The influence of physical factors on kelp and sea urchin distribution in previously and still grazed areas in the NE Atlantic. PLoS ONE 9:e0100222

Simpson RD, Smith SDA, Pople AR (1995) The effects of a spillage of diesel fuel on a rocky shore in the sub-Antarctic region (Macquarie island). Mar Poll Bull 31:367-371

Sivertsen K (1997) Geographic and environmental factors affecting the distribution of kelp beds and barren grounds and changes in biota associated with kelp reduction at sites along the Norwegian coast. Can J Fish Aquat Sci 54:2872-2887

Skadsheim A, Christie H, Leinaas HP (1995) Population reduction of Strongylocentrotus droebachiensis (Echinodermata) in Norway and possible relationships to its endoparasite Echinomermella matsi (Nematoda). Mar Ecol Prog Ser 119:199-209

Smith SDA, Simpson RD (1993) Effects of pollution on holdfast macrofauna of the kelp Ecklonia radiata: discrimination at different taxonomic levels. Mar Ecol Progr Ser 96:199-208

Waage-Nielsen E, Christie H, Rinde E (2003) Short term dispersal of kelp fauna to cleared (kelp harvested) areas. Hydrobiol 503:77-91

Wieczorek A, Dias-Brito D, Milanelli JCC (2007) Mapping oil spill environmental sensitivity in Cardoso Island State Park and surroundings areas, Sao Paulo, Brazil. Ocean Coast Manage 50:872-886

Wijkmark N, Isæus M (2010) Wave exposure calculations for the Baltic Sea. AquaBiota Report 2. 37 p. ISBN: 78-91-85975-07-5

Word JQ (2014) Environmental impacts of Arctic oil spills and Arctic spill response technologies: literature review and recommendations. Final report for the Arctic Oil Spill Response Technology - Joint Industry Programme, pp. 205

Yamamoto T, Nakaoka M, Komatsu T, Kawai H (2003) Impacts by heavy-oil spill from the Russian tanker Nakhodka on intertidal ecosystems: recovery of animal community. Mar Poll Bull 47:91-98

Zobell CE (1963) The occurrence, effects, and fate of oil polluting the sea. Air Water Pollut 7:173-197

Publisher's Note Springer Nature remains neutral with regard to jurisdictional claims in published maps and institutional affiliations. 